\title{
An Empirical Approach for Determining Longitudinal Dispersion Coefficients in Rivers
}

\author{
Sinan Sahin
}

Received: 11 November 2013 / Accepted: 19 February 2014 / Published online: 29 April 2014

(C) Springer International Publishing Switzerland 2014

\begin{abstract}
Determination of the longitudinal dispersion coefficient (LDC) of a river is needed in studies regarding cleaning the water and protecting its quality when nuclear, chemical or biological contaminants are discharged into the river. This study presents the development of an empirical equation for predicting the longitudinal dispersion coefficient in natural streams. Factors affecting the uniformity of the flow directly affect the LDC. Therefore, the hydraulic radius, defined as the ratio of the wetted area to the wetted perimeter, was considered as an important factor in determining the LDC. The presented equation relates the dispersion coefficient to hydraulic and geometric parameters of the flow, and was derived using dimensional and least squares analysis. The comparison of the predictions using 128 field data sets measured in 41 rivers in the USA has indicated that the proposed equation is reliable in predicting longitudinal dispersion coefficients in natural streams.
\end{abstract}

Keywords Longitudinal dispersion coefficient - Rivers - Contamination · Empirical equation · Hydraulic radius

\section{Introduction}

To determine the contamination risk and to control the quality of water in a reach of a stream or river, one has to estimate the concentration of the contaminants both spatially and temporally. The periodic mixing of water used for domestic, industrial and irrigation purposes, or the reuse of this water, the evaluation of the transport capacity of natural streams, the re-aeration of a stream, and many others, are among the problems needing determination of the dispersion coefficient. Therefore, the longitudinal turbulent dispersion of a solute in a stream should be investigated.

The prediction of water quality and contaminant transport fluxes in natural rivers and channels requires the solution of the mass-transport equation. Contaminants and effluents, when discharged into a river, undergo stages of mixing as the flowing water transports them downstream. The effluent is dispersed longitudinally, transversely and vertically by advective and dispersive processes. Once the cross-sectional mixing is complete, the longitudinal

\footnotetext{
S. Sahin $(\bowtie)$

Engineering Faculty, Hydraulics Division, Civil Engineering Department, Namik Kemal University, 59860 Corlu, Tekirdag, Turkey

e-mail: ssahin@nku.edu.tr
} 
dispersion becomes the most important process. In this case, the one-dimensional (1-D) dispersion equation is widely used for unsteady non-uniform flow. The general form of this equation, given by Taylor (1954), reads

$$
A\left(\frac{\partial C}{\partial t}\right)+U A\left(\frac{\partial C}{\partial x}\right)=\frac{\partial}{\partial x}\left[D_{1} A\left(\frac{\partial C}{\partial x}\right)\right]
$$

where: $A$ is the cross-sectional area of the flow $\left(\mathrm{m}^{2}\right) ; C$ is the cross-sectional average concentration $\left(\mathrm{kg} / \mathrm{m}^{3}\right) ; U$ is the cross-sectional average velocity $(\mathrm{m} / \mathrm{s}) ; t$ is the time $(\mathrm{s}) ; x$ is the direction of mean flow velocity $(\mathrm{m})$; and $D_{1}$ is the longitudinal dispersion coefficient $\left(\mathrm{m}^{2} /\right.$ $\mathrm{s}$ ). The main assumption of this equation is that the flow is homogeneous or isotropic, and the channel or river section is uniform. However, sinuosity, and sudden contractions and expansions affect uniformity. Consequently, the models based on Taylor's analysis have a clear weakness to determine the real longitudinal dispersion coefficients in rivers. Elder (1959), who followed Taylor's analysis, used a logarithmic vertical velocity profile and assumed that momentum, mass and heat transport are completely analogous to each other; the resulting model is not very accurate to determine the longitudinal dispersion coefficient in rivers, because of the adoption of the vertical logarithmic velocity profile, and other simplifications and assumptions made.

The factors that affect the uniformity of the flow directly affect the LDC. Therefore, in this work, it is accepted that the hydraulic radius, which is defined as the ratio of the cross-sectional area of the flow to the wetted perimeter, was considered an important factor in determining LDC. Consequently, a mathematical model was derived by dimensional analysis using the hydraulic radius.

A non-dimensional parameter $\beta$ is proposed for accounting for sudden contractions and expansions, as suggested by Liu (1977). Parameter $\beta$ was expressed by Liu (1977) as follows:

$$
\beta=\alpha\left(\frac{U_{*}}{U}\right)^{\gamma}
$$

where: $U_{*}$ is the shear velocity $(\mathrm{m} / \mathrm{s}) ; U$ is the mean flow velocity $(\mathrm{m} / \mathrm{s})$; and $\alpha, \gamma$ are empirical coefficients. Liu (1977) determined coefficients $\alpha, \gamma$ by least-square fitting to field data provided by Godfrey and Frederick (1970) and others.

The predicted dispersion coefficients calculated in this work were compared with measured data, as well as with the predictions of the equations by other authors listed below:

Kashefipour and Falconer (2002):

$$
\begin{gathered}
D_{1}=10.612 H U \frac{U}{U_{*}} \\
D_{1}=\left[7.428+1.775\left(\frac{W}{H}\right)^{0.62}\left(\frac{U}{U_{*}}\right)^{0.572}\right] H U\left(\frac{U}{U_{*}}\right)
\end{gathered}
$$

and Seo and Cheong (1998):

$$
\frac{D_{1}}{H U_{*}}=5.915\left(\frac{W}{H}\right)^{0.62}\left(\frac{U}{U_{*}}\right)^{1.428}
$$


Equations (3) and (4) were derived using dimensional and regression analysis, with a high correlation coefficient. The corresponding correlation coefficients $\left(\mathrm{R}^{2}\right)$ for the relationships between $D_{1}$ and $H$ (depth of flow), $W$ (channel width) and $U$ (mean flow velocity) were used to select the data sets employed in their study. In the regression analysis, they have ignored the data sets that have strong negative effect on the correlation coefficient in all cases. In their work, they have used 81 field data sets measured in 30 rivers in the USA. In this work, the same data set was used to derive a new expression for the longitudinal dispersion equation. Equation (5) was derived using dimensional analysis and a regression analysis for the one-step Huber method. 35 out of 59 measured data sets, belonging to 26 rivers in the USA, were used to establish Eq. (5); then, the equation was verified against the remaining 24 data sets.

There are many equations to predict longitudinal dispersion in natural rivers in the literature. Unfortunately, the predictions of LDC are not very accurate, and the predictions vary greatly from one equation to the other. In this work, an empirical equation was developed by dimensional analysis and least square analysis to accurately predict the LDC, which is one of the key parameter in contamination and ecosystem modeling.

\section{Evaluation of Previous Work}

Estimation of the longitudinal dispersion coefficient has received considerable attention for a long period of time (e.g., Fischer et al. 1979; Liu 1977; Seo and Cheong 1998; Guymer 1998; Kashefipour and Falconer 2002; Shucksmith et al. 2010). Various experimental studies have explored different aspects of the longitudinal dispersion (e.g., Fukuoka and Sayre 1973; Guymer 1998; Murphy et al. 2007). Moreover, regression and dimensional based analysis, along with data-driven methods, have been employed for the prediction of the dispersion coefficients, which have a wide range of variations (e.g., Seo and Cheong 1998; Kashefipour and Falconer 2002; Fischer 1968). More recently, Shahidi and Taghipour (2012) suggested a model tree (MT) which can be regarded as a robust method for classification and prediction.

Fischer $(1967,1975)$ investigated the dispersion mechanism and the role of sinuosity in natural streams, and derived theoretical and empirical equations. Fischer (1967) presented an equation to predict the longitudinal dispersion coefficient, as follows:

$$
D_{1}=-17 A \int_{0}^{W} U^{\prime}(y) H(y) \int_{0}^{y} \frac{1}{\varepsilon_{y} H(y)} \int_{0}^{y} U^{\prime}(y) H(y) d y d y d y
$$

where: $U^{\prime}$ is the spatial deviation of the velocity from the cross-sectional mean velocity $(\mathrm{m} / \mathrm{s})$, as a function of distance in the $y$-direction; $W$ is the channel width $(\mathrm{m}), y$ is the cartesian coordinate in the transverse flow direction; and $\varepsilon_{y}$ is the lateral turbulent mixing coefficient in the $y$-direction, which has been found experimentally to be typically in the region of $0.23 \mathrm{HU}_{*}$ to $0.7 \mathrm{HU}_{*}$. This relation is based on integrating the resultant of mass balance equation according to the boundary conditions. Fischer (1975) developed the following simple equation by introducing a reasonable approximation of triple integration, velocity deviation and transverse turbulent diffusion coefficient:

$$
D_{1}=\frac{0.07 U^{2} \lambda^{2}}{\varepsilon_{y}}
$$

where: $\lambda$ is the distance from the point of maximum velocity to the most distant bank. Fischer (1975) found that $U_{*}^{2} / U^{2}$ varied typically from 0.17 and 0.25 , with the mean value of 0.2 , and 
$\lambda$ was typically equal to $0.7 \mathrm{~W}$. By substituting these two values and setting $\varepsilon_{y}=0.6 \mathrm{HU}$, he concluded that $D_{1}$ could be obtained from the following equation:

$$
D_{1}=0.11\left(\frac{W^{2}}{H}\right)\left(\frac{U^{2}}{U_{*}}\right)
$$

Liu (1977) derived a dispersion coefficient equation using Fischer's Eq. (8), by taking into account the role of lateral velocity gradients in dispersion in natural streams, as follows:

$$
D_{1}=\beta \frac{0.011 U^{2} W^{2}}{H U_{*}}
$$

in which: $\beta$ is a function of both the channel cross section shape and the velocity distribution across the stream. He suggested that the parameter $\beta$ can be determined by considering sinuosity, sudden contractions and expansions, and dead zones in a natural stream. By least-square fitting to the field data obtained by Godfrey and Frederick (1970) and others, he deduced the following expression:

$$
\beta=0.18\left(\frac{U_{*}}{U}\right)^{1.5}
$$

Soft computing methods have also been applied by several investigators for the estimation of the LDC; fuzzy logic (Toprak and Savci 2007), adaptive neuro-fuzzy inference system techniques (Riahi-Madvar et al. 2009; Noori et al. 2009), support vector machine (Noori et al. 2009; Azamathulla and Ghani 2011) and genetic programming (Azamathulla and Wu 2011) are examples of these approaches. It is worth mentioning that artificial neural network (ANN) models have also been employed to predict the LDC (e.g., Tayfur and Singh 2005; Toprak and Cigizoglu 2008; Sahay 2011).

\section{Development of a New Equation}

From a review of the key literature in this field, most studies relate the longitudinal dispersion coefficient to the fluid properties, hydraulic characteristics and geometric parameters of the channel. Thus, it can be postulated that:

$$
D_{1}=f(U, H, W, U *, v, S f)
$$

where $\nu$ is the kinematic viscosity and $S f$ a shape factor (Kashefipour and Falconer 2002).

To solve Eq. (1) analytically, it is necessary to simplify this equation under some assumptions. Because of the non-linearity of the problem, a great amount of assumptions were made to solve Eq. (1) analytically. In most cases, these assumptions prevent accurate estimations of LDC. These assumptions and simplifications can be expressed as follows, according to studies in this field:

- The molecular diffusion is neglected;

- The dispersed matter is conserved;

- The flow is only in one (x) direction;

- The longitudinal turbulent diffusion term $\varepsilon_{x} \frac{\partial^{2} C}{\partial x^{2}}$ is neglected (Elder 1959); 
- $\quad \frac{\partial c^{\prime}}{\partial x} \cong 0, \frac{\partial C_{m}}{\partial x} \cong$ constant (Taylor 1953, 1954)

- $\frac{\partial C}{\partial t}=0$

- The lateral turbulent mixing coefficient $\varepsilon_{y}$, plays a much more important role than the turbulent mixing coefficient in the vertical direction $\varepsilon_{z}$ (Fischer 1967). For this reason $\varepsilon_{z}$ is neglected.

- Since the flow in natural rivers and channels is generally fully turbulent and the wall is rough, with Reynolds number effects generally being negligible, the kinematic viscosity in Eq. (11) can be ignored.

To compute the direct effect of the shape factor on the longitudinal dispersion coefficient, extensive information is required regarding the bed and wall features of a river. Furthermore, the main hydraulic parameters used to estimate $D_{1}$, such as the shear velocity, are also related to the shape factor. Dimensional analysis shows that there are many different combinations of $H, U, W$ and $U_{*}$, which can lead to the same dimensions as $D_{1}$ (Kashefipour and Falconer 2002). In this work, because of the computation difficulties of $S f$, the hydraulic radius was considered instead of $S f$ in determining LDC. Therefore, the main form of the new equation should be as follows:

$$
D_{1}=R_{h} U
$$

Because the dimension of $D_{l}$ is $\mathrm{m}^{2} / \mathrm{s}$ and the dimension of the hydraulic radius $R_{h}$ is $\mathrm{m}$, the dimension of the right-hand-side of the Eq. (12) for the LDC must be $\mathrm{m}^{2} / \mathrm{s}$ which implies $U$ is the cross-sectional velocity.

In order to incorporate the sinuosity, sudden contractions and expansions, and dead zones in the dispersion mechanism in rivers, a $\beta$ parameter is included in Eq. (12). This parameter was expressed using Eq. (2), as Liu (1977) suggested, and the numerical values of the coefficient $\alpha$ and $\gamma$ were determined by using least squares analysis, calculating the best $\beta$ value using the discrepancy ratio criteria (see section 4 for definition of discrepancy ratio) using 81 field data sets measured in 30 rivers in the USA. The data were taken from Kashefipour and Falconer (2002). The following equation was developed for the $\beta$ parameter:

$$
\beta=48\left(\frac{U}{U *}\right)^{0.47}
$$

The $\beta$ parameter was incorporated in Eq. (12) to end up with the following equation for the LDC:

$$
D_{1}=\beta R_{h} U
$$

Due to the lack of data on cross section shape, the $R_{h}$ was calculated assuming a rectangular channel section.

The river names demonstrated with bold font belong to new rivers which were used to verify the proposed equation results. KF1, KF2 and SC are the shortening of Kashefipour and Falconer (2002)-Eq. (3), Kashefipour and Falconer (2002)-Eq. (4) and Seo and Cheong (1998)-Eq. (5), respectively. There are measurements of 47 data sets belonging to 11 new rivers in the additional data sets presented in Table 1. The predictions of the new equation and the three equations are presented in Table 2 to see and to compare the results. 
Table 1 Summary of hydraulic properties, and measured and predicted longitudinal dispersion coefficients for 47 field data at 24 rivers (the data were taken from Shahidi and Taghipour 2012)

\begin{tabular}{|c|c|c|c|c|c|c|c|c|c|}
\hline & \multicolumn{5}{|c|}{ Hydraulic measurements and $\mathrm{D}_{\mathrm{m}}$ data } & \multicolumn{4}{|c|}{ Equation Predictions $\left(\mathrm{D}_{\mathrm{p}}\right)$} \\
\hline & $\mathrm{W}(\mathrm{m})$ & $\mathrm{H}(\mathrm{m})$ & $\mathrm{U}\left(\mathrm{m} / \mathrm{s}^{2}\right)$ & $\mathrm{U} *\left(\mathrm{~m} / \mathrm{s}^{2}\right)$ & $\mathrm{D}_{\mathrm{m}}\left(\mathrm{m}^{2} / \mathrm{s}\right)$ & Eq.(14) & $\mathrm{SC}$ & KF1 & $\mathrm{KF} 2$ \\
\hline Antietam Creek & 10.97 & 0.52 & 0.21 & 0.075 & 17.5 & 7.8 & 6.7 & 3.2 & 8.8 \\
\hline Antietam Creek & 23.47 & 0.7 & 0.52 & 0.101 & 101.5 & 35.5 & 38.2 & 19.8 & 88.2 \\
\hline Antietam Creek & 24.99 & 0.45 & 0.41 & 0.081 & 25.9 & 18.3 & 26.3 & 9.9 & 57.1 \\
\hline Antietam Creek & 12.8 & 0.3 & 0.42 & 0.057 & 17.5 & 14.8 & 18.0 & 9.9 & 59.8 \\
\hline Antietam Creek & 21.03 & 0.48 & 0.52 & 0.069 & 25.9 & 29.6 & 36.5 & 20.0 & 124.4 \\
\hline Monocacy river & 48.7 & 0.55 & 0.26 & 0.05 & 37.8 & 14.6 & 27.6 & 7.9 & 60.1 \\
\hline Monocacy river & 49.99 & 0.95 & 0.32 & 0.075 & 29.6 & 27.8 & 39.1 & 13.8 & 71.6 \\
\hline Monocacy river & 33.53 & 0.58 & 0.16 & 0.041 & 66.5 & 8.1 & 12.1 & 3.8 & 19.8 \\
\hline Conococheague Creek & 43.28 & 0.69 & 0.22 & 0.064 & 40.8 & 12.6 & 19.9 & 5.6 & 28.5 \\
\hline Conococheague Creek & 63.7 & 0.46 & 0.1 & 0.056 & 29.3 & 2.9 & 7.4 & 0.9 & 4.9 \\
\hline Conococheague Creek & 59.44 & 0.76 & 0.68 & 0.072 & 53.3 & 69.4 & 119.1 & 51.6 & 500.7 \\
\hline Chattahoochee river & 99.97 & 2.5 & 0.3 & 0.105 & 166.9 & 56.1 & 68.4 & 22.7 & 84.1 \\
\hline Difficult run & 11.58 & 0.4 & 0.22 & 0.087 & 1.9 & 6.1 & 6.2 & 2.3 & 7.0 \\
\hline Comite river & 15.7 & 0.2 & 0.36 & 0.04 & 69 & 9.5 & 16.3 & 6.9 & 65.3 \\
\hline Comite river & 6.1 & 0.49 & 0.25 & 0.058 & 69 & 10.1 & 6.5 & 5.6 & 14.4 \\
\hline Tangipahoa River & 42.98 & 1.28 & 0.26 & 0.068 & 45.1 & 28.3 & 30.8 & 13.5 & 52.2 \\
\hline Tangipahoa River & 31.7 & 0.76 & 0.36 & 0.053 & 44 & 30.8 & 37.1 & 19.6 & 112.8 \\
\hline Red River & 253.6 & 0.81 & 0.48 & 0.072 & 45.1 & 45.2 & 182.7 & 27.5 & 499.5 \\
\hline Red River & 161.5 & 0.4 & 0.34 & 0.02 & 44 & 24.6 & 111.7 & 24.5 & 873.8 \\
\hline Red River & 248.11 & 4.82 & 0.31 & 0.065 & 143.8 & 43.6 & 198.3 & 75.4 & 406.6 \\
\hline Copper Creek & 16.7 & 0.5 & 0.2 & 0.08 & 16.8 & 7.0 & 7.7 & 2.7 & 8.5 \\
\hline Copper Creek & 18.3 & 0.4 & 0.15 & 0.12 & 20.7 & 3.1 & 4.2 & 0.8 & 2.2 \\
\hline Powell River & 36.8 & 0.9 & 0.13 & 0.05 & 15.5 & 8.4 & 10.4 & 3.2 & 11.6 \\
\hline Clinch River & 28.7 & 0.6 & 0.35 & 0.07 & 10.7 & 20.6 & 27.2 & 11.1 & 59.3 \\
\hline Copper Creek & 19.6 & 0.8 & 0.49 & 0.1 & 20.8 & 36.7 & 33.3 & 20.4 & 75.8 \\
\hline Clinch River & 57.9 & 2.5 & 0.75 & 0.1 & 40.5 & 213.6 & 184.3 & 149.2 & 659.0 \\
\hline Conchelaa Canal & 24.7 & 1.6 & 0.66 & 0.04 & 5.9 & 167.6 & 113.1 & 184.9 & 968.2 \\
\hline Clinch river & 33.53 & 0.78 & 0.19 & 0.049 & 10.7 & 12.8 & 16.1 & 6.0 & 26.7 \\
\hline Clinch river & 55.78 & 2.26 & 0.69 & 0.099 & 36.93 & 172.6 & 154.7 & 115.6 & 510.0 \\
\hline Clinch river & 53.2 & 2.4 & 0.66 & 0.11 & 36.9 & 161.9 & 137.8 & 100.9 & 391.6 \\
\hline Copper Creek & 16.8 & 0.5 & 0.24 & 0.08 & 24.6 & 9.1 & 10.0 & 3.8 & 13.3 \\
\hline Bayou Anacoco & 25.9 & 0.9 & 0.34 & 0.07 & 32.5 & 28.9 & 28.6 & 15.8 & 63.3 \\
\hline Wind/Bighom rivers & 59.4 & 1.1 & 0.88 & 0.12 & 41.8 & 114.3 & 159.3 & 75.3 & 519.8 \\
\hline Colorado River & 106.1 & 6.1 & 0.79 & 0.089 & 181 & 581.4 & 428.0 & 458.0 & 1898.2 \\
\hline Colorado River & 71.6 & 8.2 & 1.2 & 0.337 & 243 & 698.3 & 384.3 & 372.1 & 753.8 \\
\hline Irrigation & 1.4 & 0.19 & 0.38 & 0.11 & 9.6 & 4.9 & 2.5 & 2.6 & 5.0 \\
\hline Irrigation & 1.5 & 0.14 & 0.33 & 0.1 & 1.9 & 3.3 & 2.0 & 1.6 & 3.5 \\
\hline Puneha & 5 & 0.28 & 0.26 & 0.21 & 7.2 & 3.5 & 2.8 & 1.0 & 1.7 \\
\hline Kapuni & 9 & 0.3 & 0.37 & 0.15 & 8.4 & 7.6 & 8.0 & 2.9 & 8.7 \\
\hline Kapuni & 10 & 0.35 & 0.53 & 0.17 & 12.4 & 14.2 & 14.3 & 6.1 & 20.0 \\
\hline Manganui & 20 & 0.4 & 0.19 & 0.18 & 6.5 & 3.6 & 5.2 & 0.9 & 2.3 \\
\hline
\end{tabular}


Table 1 (continued)

\begin{tabular}{|c|c|c|c|c|c|c|c|c|c|}
\hline & \multicolumn{5}{|c|}{ Hydraulic measurements and $\mathrm{D}_{\mathrm{m}}$ data } & \multicolumn{4}{|c|}{ Equation Predictions $\left(\mathrm{D}_{\mathrm{p}}\right)$} \\
\hline & $\mathrm{W}(\mathrm{m})$ & $\mathrm{H}(\mathrm{m})$ & $\mathrm{U}\left(\mathrm{m} / \mathrm{s}^{2}\right)$ & $\mathrm{U}_{*}\left(\mathrm{~m} / \mathrm{s}^{2}\right)$ & $\mathrm{D}_{\mathrm{m}}\left(\mathrm{m}^{2} / \mathrm{s}\right)$ & Eq.(14) & $\mathrm{SC}$ & KF1 & KF2 \\
\hline Waiongana & 13 & 0.6 & 0.48 & 0.24 & 6.8 & 17.5 & 15.4 & 6.1 & 14.5 \\
\hline Stony & 10 & 0.63 & 0.55 & 0.3 & 13.5 & 19.6 & 14.7 & 6.7 & 13.6 \\
\hline Waiotapu & 11.4 & 0.75 & 0.41 & 0.061 & 8 & 31.9 & 22.2 & 21.9 & 74.3 \\
\hline Manawatu & 59 & 0.72 & 0.37 & 0.07 & 32 & 27.3 & 49.4 & 14.9 & 110.0 \\
\hline Manawatu & 63 & 1 & 0.32 & 0.094 & 22 & 26.5 & 41.7 & 11.6 & 58.9 \\
\hline Manawatu & 60 & 0.95 & 0.46 & 0.092 & 47 & 43.3 & 67.3 & 23.2 & 143.5 \\
\hline
\end{tabular}

\section{Comparison of the Results}

The longitudinal dispersion coefficient varies with the shape and geometry of the channel and the parameters of the flow. Consequently, a large relative error may occur in predicting this parameter. The comparison method used follows.

The Discrepancy Ratio (Dr) was used which is defined by White et al. (1973) as follows:

$$
D r=\log _{(10)} \frac{D_{p}}{D_{m}}
$$

where: $D_{p}$ is the predicted dispersion coefficient; and $D_{m}$ is the measured dispersion coefficient. If the discrepancy ratio is between -0.3 and 0.3 , the longitudinal dispersion coefficient is predicted accurately. Accuracy was defined for this study as the proportion of numbers for which the discrepancy values is between -0.3 and 0.3 . The discrepancy ratio $(D r)$ is one of the most widely used comparison criterion method in the literature. $\mathrm{Dr}$ compares the predicted longitudinal dispersion coefficient from the corresponding measured values according to the maximum acceptable error range. This approach is considered as the most proper comparison criterion in this work. Accuracy of each equation according to the 81 field data is listed in Table 2. Among 128 data sets 81 measured data sets were selected to derive Eq. (14) and 47 measured data sets (see Table 1) were used to verify the new dispersion equation.

According to the results of Table 2, the percentage of discrepancy ratio values between 0.0 and 0.3 was $43.2 \%$ for Eq. (5), $29.6 \%$ for Eq. (4) and $18.5 \%$ for Eq. (3). These results show that Eq. (5) generally overestimated the predicted longitudinal dispersion coefficients, whereas Eqs. (3) and (4) underestimated it. On the other hand, for the proposed Eq. (14), the percentage of discrepancy values ranging between 0.0 and 0.3 were $41.9 \%$ and between -0.3 and 0.0

Table 2 Comparison of various models using the proportion of discrepancy ratio values percentage and accuracy according to the 81 field data used to derive Eq. (14)

\begin{tabular}{|c|c|c|c|c|c|}
\hline \multirow[t]{2}{*}{ Equation } & \multicolumn{4}{|c|}{$D r$ proportion $(\%)$} & \multirow[t]{2}{*}{ Accuracy $(\%)$} \\
\hline & $<-0.3$ & $-0.3-0.0$ & $0.0-0.3$ & $>0.3$ & \\
\hline Eq. (5) & 9.8 & 19.8 & 43.2 & 27.2 & 63.0 \\
\hline Eq. (3) & 28.4 & 42.0 & 18.5 & 11.1 & 60.5 \\
\hline Eq. (4) & 18.5 & 34.5 & 29.6 & 17.3 & 64.2 \\
\hline Eq. (14) & 12.4 & 28.4 & 41.9 & 17.3 & 70.3 \\
\hline
\end{tabular}


Table 3 Comparison of various models using the proportion of discrepancy ratio values percentage and accuracy according to the 47 field data used to verify Eq. (14)

\begin{tabular}{llllll}
\hline Equation & \multicolumn{2}{l}{$D r$ proportion (\%) } & Accuracy (\%) \\
\cline { 2 - 4 } & $<-0.3$ & $-0.3-0.0$ & $0.0-0.3$ & $>0.3$ & \\
\hline Eq. (5) & 27.8 & 14.9 & 29.7 & 27.6 & 44.6 \\
Eq. (3) & 55.3 & 23.4 & 8.5 & 12.8 & 31.9 \\
Eq. (4) & 14.9 & 17.0 & 17.0 & 51.1 & 34.0 \\
Eq. (14) & 27.9 & 29.7 & 21.2 & 21.2 & 50.9 \\
\hline
\end{tabular}

were $28.4 \%$. These results indicate that the predictions of the proposed Eq. (14) are slightly more accurate. This is an expected result because the whole data was used to calibrate Eq. (14).

Additional 47 field data sets from 24 rivers were used to verify Eq. (14). The results are presented in Table 3. According to these results, the proposed equation's predictions are still more accurate than those of the other models. Interestingly, Eq. (4) model overestimated the predicted longitudinal dispersion coefficients. Eq. (5) showed the second best performance in the verification process. According to the testing and verification results of the longitudinal dispersion equations, the proposed equation's results are more reliable than the other equations used in this study.

\section{Conclusions}

The main conclusions from this study can be summarized as follows:

1. For predicting longitudinal dispersion in natural rivers, the following must be taken into account in developing accurate models:

- Both vertical and lateral velocity gradients

- Non-uniformity of the river cross-section

- Secondary flows

2. Unfortunately, it is not possible to predict the longitudinal dispersion coefficient without simplifications and assumptions. Obviously, these simplifications and assumptions affect the accuracy of the models in the literature. Therefore, empirical approaches have been widely used in this field. It is thought that less assumptions and simplifications is fundamental for a highly successful model.

3. Due to lack of experimental data, the hydraulic radius was calculated with the assumption of a rectangular channel section. However, the new equation is very simple and easy to apply. Additional experimental studies are needed to fully assess the value of the new equation. However, the results of the new equation are promising. It is considered that knowing the cross section of the channel improves the success of the model.

4. The comparison of the results by using 128 sets of field data from 41 rivers in USA has indicated that the new equation is more accurate in predicting longitudinal dispersion coefficients in natural streams. In the comparisons of the results section, it is shown that the new equation calculates LDC with an accuracy of $70.3 \%$ and $50.9 \%$ in calibration and verification phases of the testing, respectively. 
Acknowledgments I would like to thank three anonymous reviewers for their valuable comments on this manuscript. An initial version of this paper was presented at the 8th International Conference of the EWRA in Porto, Portugal, June 26-29, 2013. This research is partly supported by NKUBAP.00.17.AR.13.19 project.

\section{References}

Azamathulla HM, Ghani AA (2011) Genetic programming for predicting longitudinal dispersion coefficients in streams. Water Resour Manag 25:1537-1544

Azamathulla HM, Wu FC (2011) Support vector machine approach for longitudinal dispersion coefficients in natural streams. Appl Soft Comput 11(2):2902-2905

Elder JW (1959) The dispersion of marked fluid in turbulent shear flow. J Fluid Mech 5(4):544-560

Fischer HB (1967) The mechanics of dispersion in natural streams. J Hydraul Div ASCE 93(6):187-216

Fischer HB (1968) Dispersion predictions in natural streams. J Sanit Div ASCE 94(5):927-943

Fischer HB (1975) Discussion of simple method for prediction of dispersion in streams by R.S. McQuivey and T.N. Keefer, J. Environ Eng Div ASCE 101:453-455

Fischer HB, List EJ, Koh RCY, Imberger J, Brooks NH (1979) Mixing in inland and coastal waters. Academic Press Inc, New York

Fukuoka S, Sayre W (1973) Longitudinal dispersion in sinuous channels. J Hydraul Div ASCE 99(1):195-217

Godfrey RG, Frederick BJ (1970). Stream dispersion at selected sites. Professional Rep. No. 433-K, U.S. Geological Survey

Guymer I (1998) Longitudinal dispersion in sinuous channel with changes in shape. J Hydraul Eng ASCE 124(1):33-40

Kashefipour SM, Falconer RA (2002) Longitudinal dispersion coefficients in natural streams. Water Res 36(2002):1596-1608

Liu H (1977) Predicting dispersion coefficient of stream. J Environ Eng Div ASCE 103(1):59-69

Murphy E, Ghisalberti M, Nepf H (2007) Model and laboratory study of dispersion in flows with submerged vegetation. Water Resour Res 43(5):W05438

Noori R, Karbassi AR, Farokhnia A, Dehghani M (2009) Predicting the longitudinal dispersion coefficient using support vector machine and adaptive neuro-fuzzy inference system techniques. Environ Eng Sci 26(10): $1503-1510$

Riahi-Madvar H, Ayyoubzadeh SA, Khadangi E, Ebadzadeh MM (2009) An expert system for predicting longitudinal dispersion coefficient in natural streams by using ANFIS. Expert Syst Appl 36(4):8589-8596

Sahay RR (2011) Prediction of longitudinal dispersion coefficients in natural rivers using artificial neural network. J Fluid Mech 11(3):247-261

Seo IW, Cheong TS (1998) Predicting longitudinal dispersion coefficient in natural streams. J Hydraul Eng ASCE 124(1):25-32

Shahidi AE, Taghipour M (2012) Predicting longitudinal dispersion coefficient in natural streams using M5 'model tree. J Hydraul Eng ASCE 138:542-554

Shucksmith JD, Boxall JB, Guymer I (2010) Effects of emergent and submerged natural vegetation on longitudinal mixing in open channel flow. Water Resour Res 46(4):1-14

Tayfur G, Singh VP (2005) Predicting longitudinal dispersion coefficient in natural streams by artificial neural network. J Hydraul Eng ASCE 131(11):991-1000

Taylor GI (1953) The dispersion of soluble matter in solvent flowing through a tube. Proc R Soc Lond 219A: $186-203$

Taylor GI (1954) The dispersion of matter in turbulent flow through a pipe. Proc R Soc Lond 223(A):446-468

Toprak ZF, Cigizoglu HK (2008) Predicting longitudinal dispersion coefficient in natural streams by artificial intelligence methods. Hydrol Process 22(20):4106-4129

Toprak ZF, Savci ME (2007) Longitudinal dispersion coefficient modeling in natural channels using fuzzy logic. Clean Soil Air Water 35(6):626-637

White WR, Milli H, Crabbe AD (1973) Sediment transport: an appraisal of methods. Vol 2; Hydr. Res Station Rep No IT119. Wallingford, UK 